\title{
HOW TO CREATE INDICES FOR BANK BRANCH FINANCIAL PERFORMANCE MEASUREMENT USING MCDA TECHNIQUES: AN ILLUSTRATIVE EXAMPLE
}

\author{
Fernando A. F. FERREIRA ${ }^{1}$, Sérgio P. SANTOS ${ }^{2}$, \\ Paulo M. M. RODRIGUES ${ }^{3}$, Ronald W. SPAHR ${ }^{4}$ \\ ${ }^{1}$ ISCTE Business School, BRU-IUL, University Institute of Lisbon, \\ Avenida das Forças Armadas, 1649-026 Lisbon, Portugal \\ Fogelman College of Business and Economics, University of Memphis, Memphis, \\ TN 38152-3120, USA \\ ${ }^{2}$ Faculty of Economics, University of Algarve, Campus de Gambelas, 8005-139 Faro, \\ Portugal CEFAGE, University of Évora, Portugal \\ ${ }^{3}$ Economics and Research Department, Banco de Portugal, Av. Almirante Reis 71, \\ 1150-012 Lisboa, Portugal \\ NOVA School of Business and Economics, Universidade Nova de Lisboa, \\ Portugal CEFAGE, University of Évora, Portugal \\ ${ }^{4}$ Fogelman College of Business and Economics, University of Memphis, \\ Memphis, TN 38152-3120, USA \\ E-mails: ${ }^{1}$ fernando.alberto.ferreira@iscte.pt or fernando.ferreira@memphis.edu \\ (corresponding author); ${ }^{2}$ ssantos@ualg.pt; ${ }^{3}$ pmrodrigues@bportugal.pt; \\ ${ }^{4}$ rspahr@memphis.edu
}

Received 13 April 2012; accepted 06 June 2012

\begin{abstract}
Most banks have been negatively affected by the recent economic recession, which has forced them to evaluate their operating performance including the financial performance of bank branches. Approaches that have been applied to address the financial performance evaluation of bank branches include: optimization techniques, simulations, stochastic tools, fuzzy logics and decision support systems. Although recent improvements have been made in assessing financial performance, the potential for significant further improvement remains since the recent world economic crisis is adding pressure on business margins. The purpose of this paper is to construct an exemplificative evaluation index for bank branch financial performance by integrating cognitive maps with measuring attractiveness by a categorical based evaluation technique. We aim to apply this methodology constructively to serve as a learning mechanism and introduce transparency in the decision making process. Practical applications, strengths and weaknesses of the proposed evaluation index are also discussed.
\end{abstract}

Keywords: bank branch, decision support, financial performance, cognitive maps, multiple criteria decision analysis, trade-offs.

JEL Classification: A12, E44, G20. 


\section{Introduction}

It is generally agreed that the recent economic crisis intensified world-wide competition among financial institutions. The increased intensity of competition has had direct implications in the way that banks approach customers and how they define and apply their business strategy. Under this scenario of increasing levels of instability and complexity, performance evaluation is a key function for improvement initiatives. Consequently, performance measurement plays a critical role in defining the level of success in achieving objectives and identifying where improvement efforts are required (Santos et al. 2008). In fact, the current world-wide economic crisis is placing additional pressure on business margins, and it is important for banks to consider the impact that bank branches have in the banking activity and profitability (Serna 2005; Ferreira et al. 2011a). From this premise, individual bank success and profitability may depend on its evaluation systems to measure bank branch financial performance.

The existing literature on performance evaluation of bank branches has provided an array of frameworks for financial performance measurement (e.g. DeYoung, Hasan 1998; Dekker, Post 2001; Manandhar, Tang 2002; Pastor et al. 2003; Halkos, Salamouris 2004; Camanho, Dyson 2005; Portela, Thanassoulis 2005; Wu et al. 2006; Barros et al. 2007; Li 2007) - further details on these contributions are presented in Section 1. However, despite the progress, it is generally agreed that each of the different approaches has some limitations, and there are issues which deserve further elucidation. As pointed out by Ferreira et al. (2011a), such clarification is still required in terms of criteria selection and the way compensations among criteria are calculated. This study aims to demonstrate how the integrated use of cognitive maps and measuring attractiveness by a categorical based evaluation technique (MACBETH) (Bana e Costa, Vansnick 1994; Bana e Costa et al. 2005) can overcome some of the limitations of current methodologies and support the development of bank branch financial performance evaluation indices. In doing so, it also adds to the performance evaluation literature in banking and finance (Ferreira et al. 2011c).

Our study extends the work of Ferreira et al. (2011a), and reports a sample of the discussions maintained during a two-year period with directors from the five largest banks in Portugal. It should be pointed out, however, that Ferreira et al. (2011a) dealt with bank branch performance evaluation in broad terms, while in this study we focus exclusively on the financial dimension of performance evaluation, which, from the bank's perspective, has been traditionally considered as the most important (cf. Avkiran 1995). We are unaware of any prior evidence reporting the integrated use of cognitive maps and MACBETH to support the conception of evaluation systems to measure bank branch financial performance.

The remainder of the paper is structured as follows. Section 1 presents an overview of the literature on bank branch financial performance measurement; while section 2 describes the process we have followed to design an exemplificative performance measurement index for bank branch financial evaluation. The last section concludes the paper by presenting research opportunities and concluding remarks on the use of our index for bank branch financial performance evaluation. 


\section{Bank branch financial performance evaluation}

A number of categories of performance measurement approaches have been developed to deal with bank branch performance evaluation. As discussed in Ferreira et al. (2013), these categories include: (1) traditional ratios; (2) parametric models; (3) non-parametric techniques; and (4) integrated systems for performance evaluation.

We define the first category of performance measurement approaches from studies by Barros and Leite (1996), Cyree et al. (2000), Milis and Mercken (2004), Lau and Sholihin (2005) and Tarawneh (2006), among others. This category has been the most commonly used to evaluate banking performance, because banks that report better financial ratios tend to attract a larger share of deposits and borrowers. However, Lau and Sholihin (2005) and Wu et al. (2006) are critical of ratio analysis for being lagged indicators, and potentially not providing effective conclusions when dealing simultaneously with multiple criteria.

Parametric or econometric models constitute the second category of performance evaluation methods. These methods are based on pure objectivism and require the existence of a priori cost or production functions. Despite their undeniable merit, parametric models have been criticized for difficulties in revealing and explaining causal relations among criteria, and explaining causal relationships is an important component of the present study.

Non-parametric techniques (also known as distribution-free tools) compose the third methodological category used to evaluate bank branch performance. This category of methodologies has addressed some of the limitations identified in the two previous categories. One of the most well-known non-parametric techniques is data envelopment analysis (DEA), which was introduced by Charnes et al. (1978) and has been widely and successfully used for bank branch efficiency measurement (see Dekker, Post 2001; Halkos, Salamouris 2004; Paradi, Schaffnit 2004; Camanho, Dyson 2005; Portela, Thanassoulis 2007; Yang 2009). An interesting feature of DEA is that it can handle multiple input and multiple output variables without requiring the specification of a cost or production function (cf. Beccalli et al. 2006). Nevertheless, despite its strengths and widespread use, DEA does have its shortcomings. For example, standard DEA models attribute all deviations from the frontier to inefficiency, ignoring stochastic noise in the data. Furthermore, DEA accepts the possibility of fully characterizing the production function, even knowing that some outputs are not easily measurable.

Integrated systems for performance evaluation compose the fourth category of methods and are a result of the dissatisfaction shown towards some of the previous three categories. The balanced scorecard (BSC) (Kaplan, Norton 1992) is, perhaps, the most well-known integrated system for performance evaluation. Nonetheless, the BSC has not been much explored in the banking context, and has been mainly criticized for oversimplicity and for not specifying how trade-offs among performance criteria are made explicit (cf. Brignall 1992; Neely et al. 1995; Brown 1996; Otley 1999; Davis, Albright 2004). 
Two major lines of criticism have been pointed out for all four categories of methodologies. Lovell and Pastor (1997), Manandhar and Tang (2002), Jahanshahloo et al. (2004) and Camanho and Dyson (2005) argue that the method by which performance measures are often selected can lead to the omission of important criteria, and that this can result in lack of transparency in how weights among criteria are calculated (cf. Suwignjo et al. 2000; Mihelis et al. 2001; Wu et al. 2006). In the next section, we exemplify how the integrated use of cognitive maps and MACBETH, in a bank branch financial performance context, can support the selection of evaluation criteria and deal explicitly with the trade-offs among decision criteria.

\section{Developing an index for bank branch financial performance evaluation}

The application of cognitive mapping and MACBETH in the context of performance measurement is relatively limited, and we are unaware of other documented evidence reporting their integrated use to evaluate the financial performance of bank branches. We discuss in this section how the integrated use of these techniques may be applied in the construction of an index that may be used for bank branch financial performance evaluation.

According to Ackermann and Eden (2001), Eden and Ackermann (2001b), Belton and Stewart (2002), Eden and Banville (2003) and Eden (2004), among others, cognitive mapping is an important tool for structuring and clarifying complex problems. It is generally agreed that cognitive maps are simple, interactive, motivating (depending on the degree of participant involvement) and extremely versatile. These attributes increase discussion among the actors involved; thereby, reducing the likelihood of omitted criteria and increasing transparency. Thus, cognitive mapping significantly improves the understanding of the problem and the decision aid under analysis.

Like cognitive maps, MACBETH also is an interactive technical procedure. It was created during the 1990s by Carlos Bana e Costa and Jean Claude Vansnick ( $c f$. Bana e Costa, Vansnick 1994; Bana e Costa et al. 2005) and, in general terms, it supports the construction of numerical interval scales, by providing a learning mechanism supported by visual interactive software (M-MACBETH). According to the authors, MACBETH follows a constructivist approach and is based on a simple qualitative question-answer procedure, which provides the necessary information to aid decision makers in entering the domain of cardinal measurement (for further developments, see also Belton, Stewart 2002). By bringing together humanistic, interactive and constructivist characteristics, the MACBETH approach reveals significant potential in dealing with trade-offs measurement in bank branch financial performance measurement by taking into consideration the professional experience and wisdom of bank experts.

The decision process developed in this study was organized in three main phases: (1) the structuring phase, which is focused on the development of cognitive and strategic maps necessary to support the identification of relevant criteria for bank branch financial performance evaluation; (2) the evaluation phase, which is concerned with the application of the MACBETH technique to obtain the trade-offs among evaluation 
criteria; and (3) the recommendations phase, which discusses some of the advantages and limitations of the integrated use of cognitive maps and the MACBETH approach in terms of bank branch financial performance evaluation.

\subsection{The structuring phase}

Different issues were addressed throughout the several work sessions that took place during the structuring phase of the problem. Among others, special attention was given to the definition of the panel of decision makers and actors involved, formulation of the "trigger question", design of the cognitive maps, and definition of the tree of evaluation criteria and respective descriptors and impact levels.

\subsubsection{Panel of experts and actors involved}

The definition of a panel of experts plays a critical role in the structuring process of a complex problem, namely because the experts involved, also known as decision makers, are responsible for assisting the facilitator (i.e. researcher) in the design and (desirable) implementation of the performance evaluation system.

While deciding on the dimension of the panel of decision makers, two constraints were particularly considered. The first was the limited availability of the experts to participate in the group meetings, and the second (closely related to the first) considered the difficulties in getting the panel together. Despite these constraints, the contacts established with the Ordem dos Economistas (i.e. Portuguese association of professional economists) allowed us to form a panel of six top directors from the five largest banks in Portugal. This allowed us to confront and manage different opinions on current practices of bank branch financial performance evaluation. In order to assist the facilitator in conducting the work sessions and registering the results achieved, a psychologist and a communication technician also participated in the study.

\subsubsection{Problem definition}

As previously discussed, our purpose was to integrate cognitive maps and MACBETH in order to construct an index for bank branch financial performance evaluation. Following the literature on multiple criteria decision analysis (MCDA) (cf. Belton, Stewart 2002), the analysis of the problem consisted of identifying multiple evaluation criteria and defining the respective interrelations (i.e. trade-offs among these criteria). Our index allowed us to evaluate the financial performance of bank branches, and its outputs served as comparison measures among different branches. Although the process we propose allows the ranking of bank branches, its major potential is in providing caseby-case improvement suggestions.

\subsubsection{Individual cognitive maps}

As previously stated, while deciding on the composition of the panel of decision makers, we considered the limited availability of the experts to participate in the group meetings. From this perspective, we decided to begin the structuring process with individual work sessions. As reported in the MCDA literature, this technical procedure is known 
as SODA I - a variant of the strategic options development and analysis (SODA) approach - developed by Colin Eden and Fran Ackermann ( $c f$. Eden, Ackermann 2001a, 2001b).

Each individual session began with a brief explanation of the basic concepts related to the structuring process. Careful explanations about cognitive maps were also provided to decision makers in order to avoid misunderstandings between them and the facilitator. To promote the discussion among decision maker, facilitator and psychologist, the operational phase of each individual session began with the following "trigger question": "From a financial perspective, and based on your values and professional experience, what are the main characteristics of a good bank branch?" We then applied the "post-its technique" ( $c f$. Ackermann, Eden 2001$)$ on a table $(130 \mathrm{~cm} \times 80 \mathrm{~cm})$ especially designed for the study. According to Ackermann and Eden (2001), the "post-its technique" consists of writing relevant criteria on stickers - one post-it for each criterion - and repeat the procedure until the decision maker recognizes that there are no more criteria to be considered. Later, the stickers are organized by areas of concern (i.e. clusters), and additional discussion regarding their significance should take place.

\subsubsection{Analyzing linkages between criteria}

Following earlier discussion regarding the areas of concern, we performed an internal analysis of each cluster's homogeneity (represented by stickers). The internal analysis, which is based on an interactive process among decision maker, psychologist and facilitator, allows the identification and a better understanding of the relationships among evaluation criteria. After this procedure, each expert and the communication technician registered all the links (as arrows) in the respective individual cognitive map. At the end of each individual workshop, and following Ackermann and Eden (2001), an opportunity to reflect, reshape and/or even restart the entire process was given to each of the decision makers.

\subsubsection{From the "aggregated" map to the "strategic" map}

Once the individual sessions were concluded, the research team aggregated all concepts and proposed a single collective map (or "aggregated" map). The collective map was then discussed in detail with the decision makers in a group workshop. The aggregation process of the evaluation concepts is not an easy procedural step because the criteria are often associated with different lines of thinking and, consequently, different definitions can be given to the same evaluation criteria. Therefore, as highlighted by Cossette and Audet (2003) and Ferreira et al. (2011a), among others, this critical technical procedure strongly depends on the facilitator/s' skills, and it is often considered more of an art than a science. During the group workshop, the aggregated map was presented to the panel of experts for discussion and, according to SODA I guidelines, the map served as a negotiation tool to reach a compromise solution. The process was conducted in an interactive way and, despite the difficulties, it only concluded when the panel members achieved a convergence of opinions in terms of form and content of the collective map.

Given this convergence of opinions, the final version of the collective map is called "congregated" or "strategic" map ( $c f$. Ackermann, Eden 2001; Cossette, Audet 2003). 


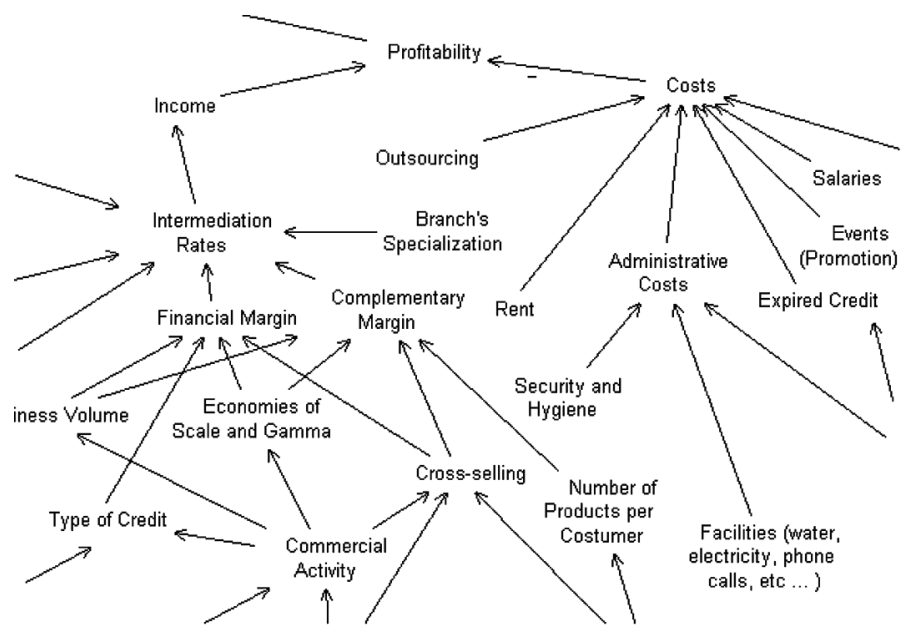

Fig. 1. Part of the strategic map

Source: Adapted from Ferreira et al. (2011a: 1325).

Figure 1 presents an outcome of the strategic map, which resulted from the negotiation and agreement reached by the panel members.

From an analysis of Figure 1, it should be noted that a map's final form and/or content depend, among other things, on the duration of the group workshop, facilitator/s' skills, actors involved and circumstances in which it was undertaken. In this sense, this procedural step is inherently subjective, which may be seen as an important shortcoming. We should bear in mind, however, that the proponents of the MCDA approach defend that all decision making is subjective and, according to Santos et al. (2002) and Ferreira et al. (2011b), one of the major values of this approach is that it makes subjectivity explicit and integrates it in a transparent way with objective data. From this perspective, the collective strategic map presented in Figure 1 should be (only) seen as a tool to obtain consolidated information on the problem, which is strongly dependent on the perceptions of a specific group of bank experts.

\subsubsection{Criteria, descriptors and impact levels}

The agreed upon strategic map allowed the group to identify two major cognitive branches of evaluation criteria: Aspects Regarding Income and Aspects Regarding Costs. Following Keeney's (1992) methodological procedures, and with the support of the M-MACBETH software, these two cognitive branches allowed us to construct a tree of criteria, which played an extremely important role in the structuring phase of our illustrative evaluation index. After checking the tree's properties, the agreement reached by the panel members allowed us to present a final version of the tree (Fig. 2).

As previously discussed, the construction of a tree of criteria through a strategic map played a very important role in the structuring phase of our evaluation index, namely because it improved the problem's clarification and the understanding of the relationships among criteria. Following the example of the cognitive mapping phase, it should 


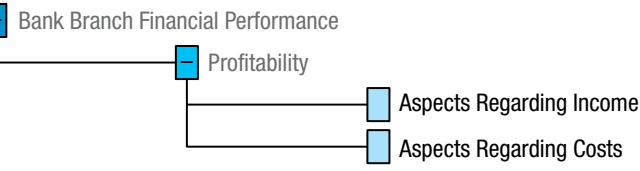

Fig. 2. Financial performance measures tree

be noted, again, that the construction of a tree of evaluation criteria is a subjective procedure, which depends on the facilitator/s' skills. As such, the transition from a strategic map to a tree's final structure is not smooth. Still, based on the high volume of information it discusses, this structuring step compensates qualified actors for their efforts and becomes easier when based on a strategic map.

Based on the cognitive branches identified herein (i.e. Aspects Regarding Income and Aspects Regarding Costs), the direct involvement of the panel members also allowed us to define two major evaluation criteria (represented in this study by $\mathrm{CRT}_{\mathrm{n}}$, with $n=$ $\{1,2\})$. The next technical procedure consisted of eliciting the construction of descriptors and impact levels for each criterion from the group. From the discussion with the experts, $\mathrm{CRT}_{1}$ (Income) is conceived to assess a bank branch's financial performance strictly based on its financial income. Income will be analyzed (and considered good or bad) based on a ratio that balances the sum of intermediation rates (financial and complementary, as illustrated in Fig. 1) and business volume (i.e. the higher the ratio the better the bank branch will be). In order to make this descriptor operational, seven ordered reference levels $\left(L_{i}\right.$ with $\left.i=1,2, \ldots, 7\right)$, including a good level and a neutral level, were also defined to better assess the degree of financial income of a certain bank branch (Table 1).

Following a similar procedure, $\mathrm{CRT}_{2}$ (Costs) is defined based on a cost to income perspective. A bank branch's cost level will be analyzed (and considered good or bad) based on a ratio that balances the sum of costs and the sum of financial income for a certain bank branch (i.e. the lower the ratio the better the bank branch will be). Fol-

Table 1. Impact levels of the descriptor of the $\mathrm{CRT}_{1}$ (Income)

\begin{tabular}{|c|c|c|}
\hline $\begin{array}{l}\text { Impact } \\
\text { levels }\end{array}$ & Monthly income & $\begin{array}{c}\text { Reference } \\
\text { levels }\end{array}$ \\
\hline$L_{1}$ & $\Sigma$ Intermediation Rates / Business Volume $\geq 2 \%$ o & \\
\hline$L_{2}$ & $1.7 \%$ o $\leq \Sigma$ Intermediation Rates / Business Volume $<2 \%$ & \\
\hline$L_{3}$ & $1.4 \% 0 \leq \Sigma$ Intermediation Rates / Business Volume $<1.7 \%$ o & Good \\
\hline$L_{4}$ & $1.1 \% \mathrm{o} \leq \Sigma$ Intermediation Rates / Business Volume $<1.4 \%$ & \\
\hline$L_{5}$ & $0.8 \%$ $\leq \Sigma$ Intermediation Rates / Business Volume $<1.1 \%$ & Neutral \\
\hline$L_{6}$ & $0.5 \% 0 \leq \Sigma$ Intermediation Rates / Business Volume $<0.8 \% 0$ & \\
\hline$L_{7}$ & $\Sigma$ Intermediation Rates / Business Volume $<0.5 \%$ & \\
\hline
\end{tabular}

Source: Adapted from Ferreira et al. (2011a: 1326). 
lowing the discussion with decision makers, $\mathrm{CRT}_{2}$ 's descriptor became operational by six ordered reference levels $\left(L_{i}\right.$ with $\left.i=1,2, \ldots, 6\right)$, including a good level and a neutral level. Once again, the professional experience of the bank experts involved in this study revealed itself extremely helpful and important to introduce realism in our performance evaluation index. Table 2 shows the descriptor and respective impact levels of $\mathrm{CRT}_{2}$.

Table 2. Impact levels of the descriptor of the $\mathrm{CRT}_{2}$ (Cost to Income)

\begin{tabular}{clc}
\hline Impact levels & \multicolumn{1}{c}{ Monthly cost to income } & Reference levels \\
\hline$L_{1}$ & $\Sigma$ (Costs) $/ \Sigma$ (Income $) \leq 25 \%$ & \\
\hline$L_{2}$ & $25 \%<\Sigma($ Costs $) / \Sigma$ (Income) $\leq 30 \%$ & \\
\hline$L_{3}$ & $30 \%<\Sigma($ Costs $) / \Sigma$ (Income $) \leq 40 \%$ & Good \\
\hline$L_{4}$ & $40 \%<\Sigma($ Costs $) / \Sigma$ (Income) $\leq 50 \%$ & Neutral \\
\hline$L_{5}$ & $50 \%<\Sigma($ Costs $) / \Sigma$ (Income $) \leq 55 \%$ & \\
\hline$L_{6}$ & $\Sigma$ (Costs) $/ \Sigma$ (Income $)>55 \%$ & \\
\hline
\end{tabular}

As can be easily seen in Tables 1 and 2 , the technical procedure adopted to turn $\mathrm{CRT}_{1}$ and $\mathrm{CRT}_{2}$ 's descriptors operational allowed sorting the impact levels in order to obtain value functions. As it is widely known in the MCDA literature, once impact levels for all descriptors have been defined, the evaluation phase is ready to start.

\subsection{The evaluation phase}

In order to obtain the decision makers' value judgements and the trade-offs among criteria, a group work session took place as described below (subsection 2.2.1). From a constructivist perspective, this group meeting was considered an important step in our decision process because trade-offs among criteria were a pre-requisite for our financial performance evaluation index. On the other hand, the index application on four bank branches served to analyze and discuss the results with and among the decision makers.

\subsubsection{Value judgements and local preferences}

As suggested by Bana e Costa et al. (2005), the construction of value judgement matrices not only supports the definition of local preference scales for each one of the criteria included in the tree (see Fig. 2), but also assists in obtaining a cardinal value function for each one of the descriptors associated with the criteria. In order to assist in filling in the matrices, and according to the guidelines presented in Bana e Costa et al. (1999), the MACBETH technique was applied based on the following categories of difference of attractiveness: $C_{0}-$ null, $C_{1}-$ very weak, $C_{2}-$ weak, $C_{3}-$ moderate, $C_{4}-$ strong, $C_{5}-$ very strong and $C_{6}$ - extreme. The mathematical procedure proposed by MACBETH consists in associating to each option/action of $X$ (with $X=\{a, b, \ldots, n\}$ being a finite set of $n$ options/actions), a value $x$ (resulting from $v():. \mathrm{X} \rightarrow \mathrm{R}$ ) such that differences $v(a)-$ $v(b)$ (with option $a$ strictly more attractive than option $b($ i.e. $a P b)$ ), are as compatible as possible with the semantic judgements made by the panel members. For example, if the panel members consider $a$ more attractive than $b$, and the value difference between 
both is extreme, then the difference of attractiveness between the two options should be allocated to $C_{6}$. Based on the panel members' judgements, the technique will propose, if possible, an initial scale that satisfies formulations (1) and (2) (cf. Junior 2008):

$$
\begin{gathered}
\forall a, b \in X: v(a)>v(b) \Leftrightarrow a P b \\
\forall k, k^{*} \in\{1,2,3,4,5,6\}, \forall a, b, c, d \in X \text { with }(a, b) \in C_{k} \\
\text { and }(c, d) \in C_{k^{*}}: k \geq k^{*}+1 \Rightarrow v(a)-v(b) \geq v(c)-v(d) .
\end{gathered}
$$

From a logical perspective, formulation (1) considers that if action $a$ is strictly more attractive than action $b$ (i.e. $a P b)$, then its value should be greater than the value of action $b$. In this sense, it is possible to associate numbers to these two actions such that $v(a)>v(b)$. Similarly, if both actions are indifferent (i.e. $a I b)$, then $v(a)=v(b)$ and the pair $(a, b)$ is allocated to $C_{0}$. Complementarily, and based on the semantic categories $C_{k}$ identified before, formulation (2) asserts "that all of the differences allocated to one semantic preference difference category are strictly larger than those allocated to a lower category" (Bana e Costa et al. 2008). Figure 3 exemplifies this technical procedure.

If the decision makers' value judgements are consistent with (1) and (2), linear programming is then applied according to (3) (cf. Junior 2008), and an initial scale is proposed for discussion:

$\operatorname{Min} v(n)$

$$
\begin{aligned}
& \text { S.T.: } \forall a, b \in X: a P b \Rightarrow v(a) \geq v(b)+1 \\
& \forall a, b \in X: a I b \Rightarrow v(a)=v(b) \\
& \forall(a, b),(c, d) \in X \text {, if the difference of attractiveness between } \\
& a \text { and } b \text { is bigger than between } c \text { and } d \text {, then: } \\
& v(a)-v(b) \geq v(c)-v(d)+1+\delta(a, b, c, d)
\end{aligned}
$$

$v\left(a^{-}\right)=0$,

where:

$n$ is an element of $X$ so that $\forall a, b, c, \ldots \in X: n(P \cup I) a, b, c, \ldots$

$a^{-}$is an element of $X$ so that $\forall a, b, c, \ldots \in X: a, b, c, \ldots(P \cup I) a^{-}$

$\delta(a, b, c, d)$ is the minimal number of categories of difference of attractiveness

between the difference of attractiveness between $a$ and $b$ and the

difference of attractiveness between $c$ and $d$.

Technically, formulation (3) aims to minimize the value of $n$ in order to guarantee the minimal length of the initial scale. More specifically, it should be emphasized that $n$ represents the most attractive (or at least as attractive as the others) element of $X$ (i.e. $n(P \cup I) a, b, c, \ldots)$. On the other hand, $a^{-}$represents the least attractive (or at least as attractive as the others) element of $X$ (i.e. $\left.a, b, c, \ldots(P \cup I) a^{-}\right)$, and its value is anchored to the "zero" of the scale (for further discussion, see Bana e Costa et al. 2008).

For practicality, the filling process of the value judgement matrices should be repeatedly executed until each descriptor's local preference scale is defined. Figure 4 illustrates the 


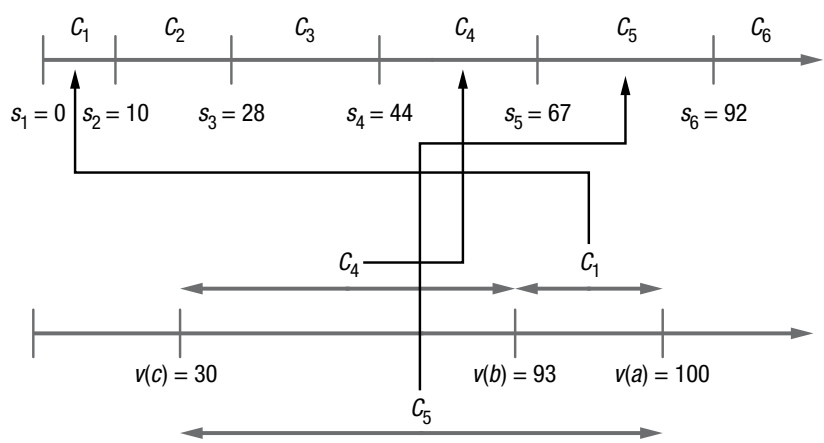

Fig. 3. Example of numerical representations of semi-orders for multiple thresholds Source: Mello et al. (2002: 57).

matrix and the value function obtained for the $\mathrm{CRT}_{1}$ 's descriptor (see Table 1), which were discussed and approved by the experts involved in our study.

At this stage of the process, the M-MACBETH software was extremely useful in identifying value judgement inconsistencies, which were promptly overcome based on further discussion and value judgement reconsideration from the experts (for further details, see Bana e Costa, Chagas 2004). Following the same technical procedure used for $\mathrm{CTR}_{1}$, Figure 5 shows the matrix and the value function obtained for the $\mathrm{CRT}_{2}$ 's descriptor (see Table 2), which were also discussed and approved by the panel members.

\begin{tabular}{|c|c|c|c|c|c|c|c|c|}
\hline \multicolumn{8}{|c|}{ 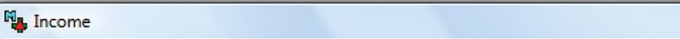 } & $5 x$ \\
\hline 戋 & L1 & L2 & L3 & L4 & L5 & L6 & $\mathrm{L7}$ & $\begin{array}{l}\text { Current } \\
\text { scale }\end{array}$ \\
\hline L1 & no & very weak & weak & moderate & strong & v. strong & v. strong & 180 \\
\hline $\mathrm{L} 2$ & & no & weak & moderate & strong & v. strong & v. strong & 160 \\
\hline L3 & & & no & weak & moderate & strong & strong & 100 \\
\hline L4 & & & & no & weak & moderate & strong & 56 \\
\hline L5 & & & & & no & weak & moderate & 0 \\
\hline L6 & & & & & & no & weak & -60 \\
\hline$L 7$ & & & & & & & no & -100 \\
\hline \multicolumn{9}{|c|}{ Consistent judgements } \\
\hline 围? & (7) & 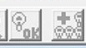 & 四㫜: & $H_{1}^{-1}$ & 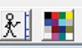 & & & \\
\hline
\end{tabular}

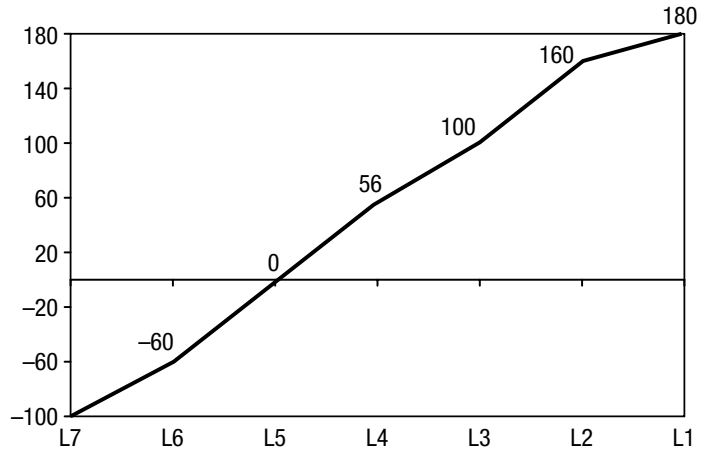

Fig. 4. Value judgements, proposed scales and value function of the $\mathrm{CRT}_{1}$ (Income) Source: Adapted from Ferreira et al. (2011a: 1327). 


\begin{tabular}{|c|c|c|c|c|c|c|c|}
\hline \multicolumn{7}{|c|}{ 댈. Costs } & $x^{3}$ \\
\hline 凅 & L1 & L2 & L3 & L4 & L5 & L6 & $\begin{array}{l}\text { Current } \\
\text { scale }\end{array}$ \\
\hline L1 & no & very weak & moderate & strong & v. strong & extreme & 175 \\
\hline L2 & & no & weak & moderate & strong & v. strong & 150 \\
\hline $\mathrm{L} 3$ & & & no & weak & moderate & strong & 100 \\
\hline L4 & & & & no & weak & moderate & 50 \\
\hline L5 & & & & & no & weak & 0 \\
\hline L6 & & & & & & no & -50 \\
\hline \multicolumn{8}{|c|}{ Consistent judgements } \\
\hline 界 & & 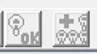 & 田阴动 & ${ }^{-1}-$ 思F & 影 & & \\
\hline
\end{tabular}

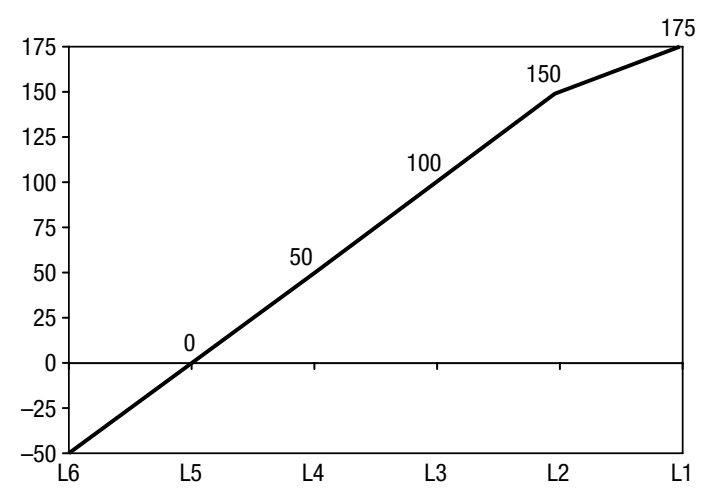

Fig. 5. Value judgements, proposed scales and value function of the $\mathrm{CRT}_{2}$ (Cost to Income)

Following the discussion presented herein, it is important to underline that mutual preferential independence tests (see Bana e Costa, Chagas 2004; Bana e Costa et al. 2005) were also conducted to guarantee preferential independence between $\mathrm{CRT}_{1}$ and $\mathrm{CRT}_{2}$. The definition of cardinal value scales for both descriptors (see Figs 4 and 5) is an important phase of our decision problem. However, it only allows partial assessment of bank branches and, to get an overall assessment, trade-offs between the two criteria (also known as substitution rates or weights) need to be obtained.

\subsubsection{The trade-off procedures}

In order to obtain the substitution rates between $\mathrm{CRT}_{1}$ and $\mathrm{CRT}_{2}$, the panel members were asked to rank the criteria in terms of their overall attractiveness. For this purpose, a matrix of cognitive comparisons was created, where an alternative $a_{0}$ (composed of the worst impact levels) was compared to an alternative $a_{n}$ (composed of the best impact levels) ( $c f$. Bana e Costa, Chagas 2004). Once ordered $\mathrm{CRT}_{1}$ and $\mathrm{CRT}_{2}$, with $\mathrm{CRT}_{1}$ considered overall preferable to $\mathrm{CTR}_{2}$, the experts were asked to express their value judgements in terms of the difference of attractiveness between both criteria. Following the procedure used for the local scales ( $c f$. Figs 4 and 5), a MACBETH scale and respective weights were obtained and proposed for discussion (Fig. 6).

The process of weighting $\mathrm{CRT}_{1}$ and $\mathrm{CRT}_{2}$ was conducted using the M-MACBETH software, which enabled the construction of an additive value model as presented in (4) (cf. Bana e Costa et al. 2008). This additive model allows partial scores $v_{i}(a)$ to be 


\begin{tabular}{|c|c|c|c|c|c|c|c|c|c|}
\hline \multicolumn{6}{|c|}{ 路, Weighting (Overall) } & \multicolumn{4}{|c|}{ Weighting (Overall) } \\
\hline$\frac{\text { 畻 }}{\text { [ CRT1 ] }}$ & $\frac{\text { [CRT1 ] }}{\text { no }}$ & $\frac{\text { [CRT2 ] }}{\text { very weak }}$ & $\frac{\text { [ all lower ] }}{\text { ४. strong }}$ & $\begin{array}{l}\begin{array}{c}\text { Current } \\
\text { scale }\end{array} \\
54.55\end{array}$ & & & $\begin{array}{c}\text { Current } \\
\text { scale }\end{array}$ & $\begin{array}{r}\text { MACBETH } \\
\text { anchored } \\
\end{array}$ & $\begin{array}{c}\text { MACBETH } \\
\text { basic }\end{array}$ \\
\hline [ CRT2] & & no & $\psi$. strong & 45.45 & & [ CRT1] & 54.55 & 54.55 & 6.00 \\
\hline [ all lower ] & & & no & 0.00 & & [CAT2] & 45.45 & 45.45 & 5.00 \\
\hline \multicolumn{6}{|c|}{ Consistent judgements } & [ all lower ] & 0.00 & 0.00 & 0.00 \\
\hline
\end{tabular}

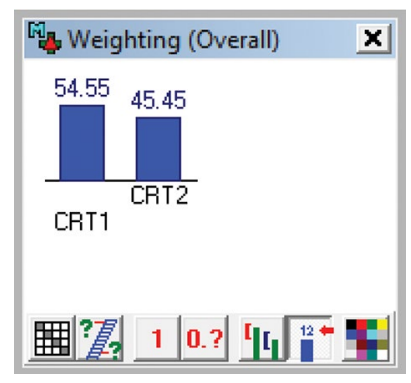

Fig. 6. Value judgements, proposed scales and criteria weights

Source: Adapted from Ferreira (2013).

aggregated and the overall score $V(a)$ (i.e. our exemplificative evaluation index) to be calculated:

$$
V(a)=\sum_{i=1}^{n} x_{i} v_{i}(a) \text { with } \sum_{i=1}^{n} x_{i}=1 \text { and } x_{i}>0 \text { and }\left\{\begin{array}{l}
v_{i}\left(\operatorname{good}_{i}\right)=100 \\
v_{i}\left(\text { neutral }_{i}\right)=0
\end{array} .\right.
$$

It should be noted that $\operatorname{good}_{i}$ and neutral ${ }_{i}$ are two specific impact levels that aim to facilitate cognitive comparisons, such that $v_{i}\left(\operatorname{good}_{i}\right)=100$ and $v_{i}\left(\right.$ neutral $\left._{i}\right)=0$. Based on the discussion with the panel members, it became possible to approve the trade-offs and assess bank branches' partial and overall financial performance.

\subsubsection{Measuring bank branch financial performance}

Since our evaluation index is very simple and merely exemplificative, it should serve only as a guideline. However, in order to test our index in a real context, and proceed with the bank branch financial performance measurement, financial information regarding bank branches was formally requested to Caixa Geral de Depósitos (CGD). CGD is the only Portuguese public bank and one of the top-five banks operating in the country. At this point, it seems opportune to highlight that information on four CGD bank branches (called Alphas) was randomly and anonymously provided by the bank's administration. Still, the information provided, which referred to a one-month period, was extremely useful, not only to test our index but also to increase the interest and, thus, the discussion among the panel members.

Based on the descriptors and on the value functions previously obtained for $\mathrm{CRT}_{1}$ and $\mathrm{CRT}_{2}$ ( $c f$. Figs 4 and 5), the first measurement step consisted of calculating partial financial performance values for each one of the four bank branches under study (Table 3 ). 
Table 3. Levels and partial values revealed by the evaluated branches

\begin{tabular}{ccccc} 
& \multicolumn{2}{c}{ CRT $_{1}$} & \multicolumn{2}{c}{ CRT $_{2}$} \\
\hline Alpha 1 & $L_{5}$ & 0 & $L_{1}$ & 175 \\
\hline Alpha 2 & $L_{4}$ & 56 & $L_{1}$ & 175 \\
\hline Alpha 3 & $L_{3}$ & 100 & $L_{1}$ & 175 \\
\hline Alpha 4 & $L_{3}$ & 100 & $L_{3}$ & 100 \\
\hline Good & $L_{3}$ & 100 & $L_{3}$ & 100 \\
\hline Neutral & $L_{5}$ & 0 & $L_{5}$ & 0 \\
\hline
\end{tabular}

To better understand the results shown in Table 3, it should be noted that Good and Neutral are two fictitious bank branches that aim to facilitate cognitive comparisons. Good represents a bank branch that performs at a good level for $\mathrm{CRT}_{1}$ and $\mathrm{CRT}_{2}$, and Neutral stands for a bank branch that performs at neutral levels (i.e. is neither attractive nor unattractive) for both criteria involved. At this stage, performance comparisons among branches became possible (e.g. Alpha 1 reveals the worst performance level of the criterion $\mathrm{CRT}_{1}$, which corresponds to the neutral level, but it also reveals the best performance level of the criterion $\mathrm{CRT}_{2}$ ). These performance comparisons are useful for two reasons. First, they enable decision makers to better understand the evaluation process and, if possible, propose and/or implement local improvement suggestions. Second, as a consequence, local improvements resulting from the comparisons will influence the overall performance of the bank branches. To obtain the global attractiveness values, local ratings are aggregated based on the additive model presented in (4). Table 4 presents the partial and overall performance values of the six bank branches analyzed (Good and Neutral included).

Table 4. Partial values and overall attractiveness revealed by the evaluated branches

\begin{tabular}{cccc} 
& Global & CRT $_{1}$ & CRT $_{2}$ \\
\hline Alpha 1 & 79.54 & 0 & 175 \\
\hline Alpha 2 & 110.09 & 56 & 175 \\
\hline Alpha 3 & 134.09 & 100 & 175 \\
\hline Alpha 4 & 100 & 100 & 100 \\
\hline Good & 100 & 100 & 100 \\
\hline Neutral & 0 & 0 & 0 \\
\hline \multicolumn{2}{c}{ Weights } & 0.5455 & 0.4545 \\
\hline
\end{tabular}

A financial performance ranking results from the values presented in Table 4. As can be observed, Alpha 3 is revealed to be the best branch with an overall score of 134.09. Contrarily, Alpha 1 offers the worst performance with an overall score of 79.54. However, and despite of the results, special emphasis should be given to the constructive analysis and discussion that emerged among the decision makers. 


\subsubsection{Analyzing results}

The construction of our bank branch financial performance evaluation index allowed to: (1) discriminate bank branches according to the panel members' value judgements; (2) compare the branches' performance with the Good and Neutral references; (3) promote discussion among experts and, therefore, increase transparency in the decision making process; (4) serve as learning mechanism and basis for improvement discussions; and (5) demonstrate how cognitive mapping and MACBETH can be integrated in a bank branch financial evaluation context.

As discussed by Bana e Costa and Chagas (2004) and Ferreira et al. (2011a), among others, once a final ranking is approved by the panel members, the evaluation phase may be considered completed. Nonetheless, additional analyses (e.g. sensitivity and robustness analyses) are strongly encouraged not only to validate the results and analyze their stability, but also to promote extra discussion, which should serve as basis for recommendations. Figure 7 shows the robustness analysis developed in our study.
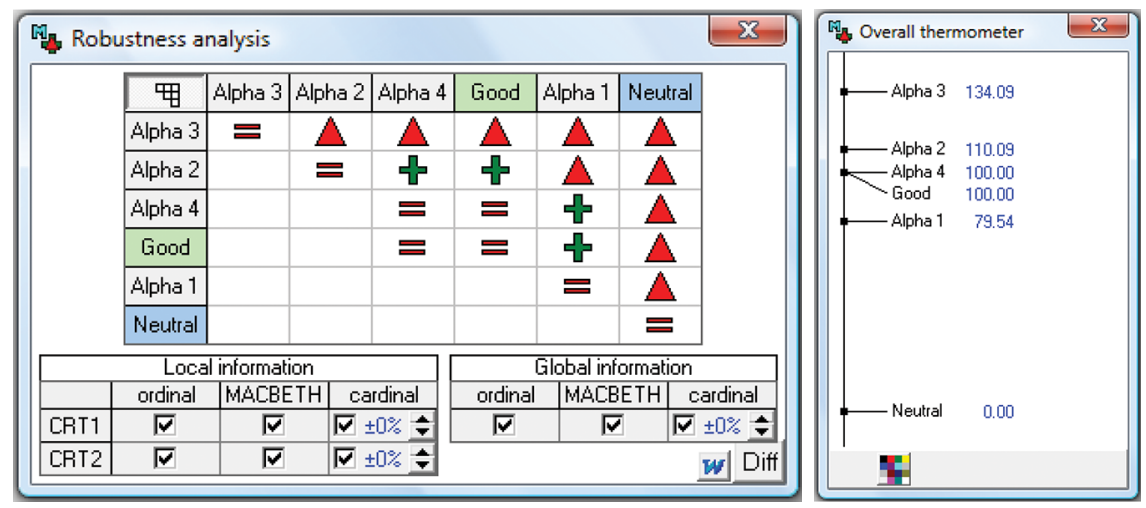

Fig. 7. Robustness analysis and overall thermometer

In order to better understand the robustness analysis carried out during our study, which was supported by the M-MACBETH software, it seems important to clarify that each triangle represents a classic dominance of one bank branch over the others (e.g. independently of the trade-offs obtained, Alpha 3 dominates the other bank branches in terms of partial and overall performance). On the other hand, each cross stands for an additive dominance situation, meaning that in spite of a better overall performance, a bank branch does not present the best local performance in both criteria (e.g. Alpha 4 (with an overall score of 100) is overall more attractive than Alpha 1 (with an overall score of 79.54), but Alpha 4 performance on $\mathrm{CTR}_{2}$ (i.e. 100) is worse than Alpha 1 performance on the same criterion (i.e. 175)) ( $c f$. Table 4). As expected, situations of additive dominance are possible because of the trade-offs between $\mathrm{CTR}_{1}$ and $\mathrm{CTR}_{2}$. With proper reservation, the robustness analysis carried out in our study indicated that the illustrative financial index we have developed, whilst very simple, was robust in assessing the 4 bank branches. This information became extremely useful to promote 
discussion among experts, to highlight the potential of using the process we propose to develop more comprehensive indices, and to increase interest on the part of the decision makers for a practical implementation of the framework.

\subsection{The recommendation phase of the study}

Based on the receptiveness and satisfaction expressed by the panel members, the results presented herein may be considered encouraging. Nonetheless, it is important to emphasize that this study is process-oriented where a non-prescriptive position has been assumed. As such, and despite of its flexibility and versatility, our financial performance evaluation index is merely exemplificative, and should be seen as a learning mechanism and not as a tool to prescribe optimal solutions. Furthermore, it is important to bear in mind that the development of any index to assess the financial performance of bank branches will inevitably depend on the context and actors involved and, as a consequence, generalizations to other contexts or group of decision makers should be carefully analyzed. Our main objective and contribution was to provide evidence that the integrated use of cognitive mapping and MCDA can be a very insightful and important process for the development of performance indicators to assess the financial performance of bank branches.

\section{Concluding remarks}

A multiple criteria decision analysis (MCDA) framework for bank branch financial performance evaluation has been developed in this study. This process-oriented mechanism allows bank branch performance to be evaluated based on bank experts' perceptions and professional banking experience.

Although recent progress in decision analysis has occurred, searching for optimal solutions for complex problems as this one seems to be unrealistic because of criteria selection difficulties and the fact that trade-offs among those criteria are debatable and remain open issues. In our study, the integrated use of cognitive mapping and MACBETH allowed us to support criteria selection and obtain compensation rates. By focusing exclusively on the financial dimension of the performance evaluation, which has been traditionally considered the most important (cf. Kaplan, Norton 1992; Avkiran 1995), we extend the research of Ferreira et al. (2011a) and report part of the results of the interaction maintained during a two-year period with directors from the five largest banks in Portugal. We are unaware of any prior evidence reporting the integrated use of these two methodologies to support the conception of evaluation systems for bank branch financial performance.

As discussed above, the financial performance evaluation index developed in our study is merely exemplificative, but it may be useful to: (1) monitor bank branches' progress over time; (2) identify and desirably implement corrective actions; (3) increase transparency in the way evaluation criteria are selected and the way compensations among criteria are obtained; and (4) incorporate the experts' knowledge and understanding in the decision making process, which increase the realism of the final evaluation. 
Our results are encouraging but, due to their strong dependence on the context and/or decision makers involved, they should be considered with proper reservation. In fact, as previously stated, the framework we propose in this study is not without its own limitations. Nonetheless, at least in the MCDA context, it is widely known that no superior methodological approach exists and that the choice of method is strongly dependent on the decision context (for further discussion, see Weber, Borcherding 1993; Ananda, Herath 2009). In this sense, further research and/or case studies are strongly encouraged in terms of: (1) conducting a panel study with a different set of bank experts; (2) conducting a panel study within a different country; and/or (3) creating a survey to receive feedback from more than just a few managers. We trust that improvements will strengthen the potential and interest of our evaluation index.

\section{Acknowledgements}

The second author of this paper acknowledges funding support by Fundação para a Ciência e a Tecnologia (SFRH/BSAB/1196/2011 and FEDER/COMPETE grant Pest-C/ EGE/UI4007/2011).

\section{References}

Ackermann, F.; Eden, C. 2001. SODA - Journey making and mapping in practice, in J. Rosenhead, J. Mingers (Eds.). Rational analysis for a problematic world revisited: problem structuring methods for complexity, uncertainty and conflict. 2nd ed. Chichester: John Wiley \& Sons, 43-60.

Ananda, J.; Herath, G. 2009. A critical review of multi-criteria decision making methods with special reference to forest management and planning, Ecological Economics 68(10): 2535-2548. http://dx.doi.org/10.1016/j.ecolecon.2009.05.010

Avkiran, N. 1995. A multivariate model of integrated branch performance and potential focusing on personal banking. $\mathrm{PhD}$ thesis. Melbourne: Victoria University of Technology [online], [cited17 February 2012]. Available from Internet: http://vuir.vu.edu.au/15434/1/Avkiran_1995_ compressed.pdf

Bana e Costa, C.; Chagas, M. 2004. A career choice problem: an example of how to use MACBETH to build a quantitative value model based on qualitative value judgements, European Journal of Operational Research 153(2): 323-331. http://dx.doi.org/10.1016/S0377-2217(03)00155-3

Bana e Costa, C.; De Corte, J.; Vansnick, J. 2005. On the mathematical foundations of MACBETH, in J. Figueira, S. Greco, M. Ehrgott (Eds.). Multiple criteria decision analysis: the state of the art surveys. New York: Springer, 409-442.

Bana e Costa, C.; Ensslin, L.; Corrêa, E.; Vansnick, J. 1999. Decision support systems in action: Integrated application in a multicriteria decision aid process, European Journal of Operational Research 113(2): 315-335. http://dx.doi.org/10.1016/S0377-2217(98)00219-7

Bana e Costa, C.; Lourenço, J.; Chagas, M.; Bana e Costa, J. 2008. Development of reusable bid evaluation models for the Portuguese electric transmission company, Decision Analysis 5(1): 22-42. http://dx.doi.org/10.1287/deca.1080.0104

Bana e Costa, C.; Vansnick, J. 1994. MACBETH: an interactive path towards the construction of cardinal value functions, International Transactions in Operational Research 1(4): 489-500. http://dx.doi.org/10.1016/0969-6016(94)90010-8

Barros, C.; Ferreira, C.; Williams, J. 2007. Analysing the determinants of performance of best and worst European banks: a mixed logit approach, Journal of Banking and Finance 31(7): 2189-2203. http://dx.doi.org/10.1016/j.jbankfin.2006.11.010 
Barros, P.; Leite, A. 1996. Competition in Portuguese commercial banking, Economica 20(1): 7-30.

Beccalli, E.; Casu, B.; Girardon, C. 2006. Efficiency and stock performance in European banking, Journal of Business Finance \& Accounting 33(1/2): 245-262.

http://dx.doi.org/10.1111/j.1468-5957.2006.01362.x

Belton, V.; Stewart, T. 2002. Multiple criteria decision analysis: an integrated approach. Dordrecht: Kluwer Academic Publishers. http://dx.doi.org/10.1007/978-1-4615-1495-4

Brignall, S. 1992. Performance measurement systems as change agents: a case for further research, Research Paper 72. Warwick: Warwick Business School.

Brown, M. 1996. Keeping score: using the right metrics to drive world-class performance. New York: Quality Resources.

Camanho, A.; Dyson, R. 2005. Cost efficiency measurement with price uncertainty: a DEA application to bank branches assessments, European Journal of Operational Research 161(2): 432-446. http://dx.doi.org/10.1016/j.ejor.2003.07.018

Charnes, A.; Cooper, W.; Rhodes, E. 1978. Measuring the efficiency of decision making units, European Journal of Operational Research 2(6): 429-444.

http://dx.doi.org/10.1016/0377-2217(78)90138-8

Cossette, P.; Audet, M. 2003. Qu'est qu'une carte cognitive?, in P. Cossette (Ed.). Cartes cognitives et organizations, Les Éditions de L'ADREG, 31-60 [online], [cited 17 February 2012]. Available from Internet:/ http://web.hec.ca/airepme/images/File/Livres/adreg_05.pdf

Cyree, K.; Wansley, J.; Boehm, T. 2000. Determinants of bank growth choice, Journal of Banking and Finance 24(5): 709-734. http://dx.doi.org/10.1016/S0378-4266(99)00049-7

Davis, S.; Albright, T. 2004. An investigation of the effect of the balanced scorecard implementation on financial performance, Management Accounting Research 15(2): 135-153.

http://dx.doi.org/10.1016/j.mar.2003.11.001

Dekker, D.; Post, T. 2001. A quasi-concave DEA model with an application for bank branch performance evaluation, European Journal of Operational Research 132(2): 296-311.

http://dx.doi.org/10.1016/S0377-2217(00)00153-3

DeYoung, R.; Hasan, I. 1998. The performance of the novo commercial banks: a profit efficiency approach, Journal of Banking and Finance 22(5): 565-587.

http://dx.doi.org/10.1016/S0378-4266(98)00025-9

Eden, C. 2004. Analyzing cognitive maps to help structure issues or problems, European Journal of Operational Research 159(3): 673-686. http://dx.doi.org/10.1016/S0377-2217(03)00431-4

Eden, C.; Ackermann, F. 2001a. Group decision and negotiation in strategy making, Group Decision and Negotiation 10(4): 119-140. http://dx.doi.org/10.1023/A:1008710816126

Eden, C.; Ackermann, F. 2001b. SODA - the principles, in J. Rosenhead, J. Mingers (Eds.). Rational analysis for a problematic world revisited: problem structuring methods for complexity, uncertainty and conflict. 2nd ed. Chichester: John Wiley \& Sons, 21-41.

Eden, C.; Banville, C. 2003. Construction d'une vision stratégique au moyen de la cartographie cognitive assisté par ordinateur, in P. Cossette (Eds.). Cartes cognitives et organisations, Les Éditions de L'ADREG 125-166 [online], [cited 17 February 2012]. Available from Internet: http:// web.hec.ca/airepme/images/File/Livres/adreg_05.pdf

Ferreira, F. 2013. Measuring trade-offs among criteria in a balanced scorecard framework: possible contributions from the multiple criteria decision analysis research field, Journal of Business Economics and Management 14(3): 433-447. http://dx.doi.org/10.3846/16111699.2011.631744

Ferreira, F.; Santos, S.; Rodrigues, P. 2011a. Adding value to bank branch performance evaluation using cognitive maps and MCDA: a case study, Journal of the Operational Research Society 62(7): 1320-1333. http://dx.doi.org/10.1057/jors.2010.111 
Ferreira, F.; Santos, S.; Rodrigues, P. 2011b. From traditional operational research to multiple criteria decision analysis: basic ideas on an evolving field, Problems and Perspectives in Management 9(3): 114-121.

Ferreira, F.; Santos, S.; Rodrigues, P.; Spahr, R. 2013. Evaluating retail banking service quality and convenience with MCDA techniques: a case study at the bank branch level, Journal of Business Economics and Management. 15(1): 1-21. http://dx.doi.org/10.3846/16111699.2012.673504

Ferreira, F.; Spahr, R.; Pereira, J. 2011c. New banking trends, MCDA and financial decisions: insights and a framework for retail banking, Banks and Bank Systems 6(2): 23-35.

Halkos, G.; Salamouris, D. 2004. Efficiency measurement of the Greek commercial banks with the use of financial ratios: a data envelopment analysis approach, Management Accounting Research 15(2): 201-224. http://dx.doi.org/10.1016/j.mar.2004.02.001

Jahanshahloo, G.; Amirteimoori, A.; Kordrostami, S. 2004. Multi-component performance, progress and regress measurement and shared inputs and outputs in DEA for panel data: an application in commercial bank branches, Applied Mathematics and Computation 151(1): 1-16.

http://dx.doi.org/10.1016/S0096-3003(03)00318-7

Junior, H. 2008. Multicriteria approach to data envelopment analysis, Pesquisa Operacional 28(2): 231-242.

Kaplan, R.; Norton, D. 1992. The balanced scorecard: measures that drive performance, Harvard Business Review 70(1): 71-79.

Keeney, R. 1992. Value-focused thinking: a path to creative decisionmaking. Harvard: Harvard University Press.

Lau, C.; Sholihin, M. 2005. Financial and non-financial performance measures: how do they affect job satisfaction? British Accounting Review 37(4): 389-413.

http://dx.doi.org/10.1016/j.bar.2005.06.002

Li, C. 2007. Problems in bank branch inefficiency: management, scale and location, Asian Journal of Management and Humanity Sciences 1(4): 523-538.

Lovell, C.; Pastor, J. 1997. Target setting: an application to a bank branch network, European Journal of Operational Research 98(2): 290-299. http://dx.doi.org/10.1016/S0377-2217(96)00348-7

Manandhar, R.; Tang, J. 2002. The evaluation of bank branch performance using data envelopment analysis: a framework, Journal of High Technology Management Research 13(1): 1-17. http://dx.doi.org/10.1016/S1047-8310(01)00045-1

Mello, J.; Gomes, E.; Lins, M. 2002. Análise multicritério da presença da universidade federal fluminense com o uso do método MACBETH, Produção 11(2): 53-67.

http://dx.doi.org/10.1590/S0103-65132001000200004

Mihelis, G.; Grigoroudis, E.; Siskos, Y.; Politis, Y.; Malandrakis, Y. 2001. Customer satisfaction measurement in the private bank sector, European Journal of Operational Research 130(2): 347-360. http://dx.doi.org/10.1016/S0377-2217(00)00036-9

Milis, K.; Mercken, R. 2004. The use of balanced scorecard for the evaluation of information and communication technology projects, International Journal of Project Management 22(2): 87-97. http://dx.doi.org/10.1016/S0263-7863(03)00060-7

Neely, A.; Gregory, M.; Platts, K. 1995. Performance measurement system design: a literature review and research agenda, International Journal of Operations and Production Management 15(4): 80-116. http://dx.doi.org/10.1108/01443579510083622

Otley, D. 1999. Performance management: a framework for management control system research, Management Accounting Research 10(4): 363-382. http://dx.doi.org/10.1006/mare.1999.0115 
Paradi, J.; Schaffnit, C. 2004. Commercial branch performance evaluation and results communication in a Canadian bank: a DEA application, European Journal of Operational Research 156(3): 719-735. http://dx.doi.org/10.1016/S0377-2217(03)00108-5

Pastor, J.; Lovell, C.; Tulkens, H. 2003. Evaluating the financial performance of bank branches, Working Paper. Centro de Investigación Operativa. Alicante: Universidad Miguel Hernández.

Portela, M.; Thanassoulis, E. 2005. Profitability of a sample of Portuguese bank branches and its decomposition into technical and allocative components, European Journal of Operational Research 162(3): 850-866. http://dx.doi.org/10.1016/j.ejor.2003.10.018

Portela, M.; Thanassoulis, E. 2007. Comparative efficiency analysis of Portuguese bank branches, European Journal of Operational Research 177(2): 1275-1288.

http://dx.doi.org/10.1016/j.ejor.2006.01.007

Santos, S.; Belton, V.; Howick, S. 2002. Adding value to performance measurement by using systems dynamics and multicriteria analysis, International Journal of Operations \& Production Management 22(11): 1246-1272. http://dx.doi.org/10.1108/01443570210450284

Santos, S.; Belton, V.; Howick, S. 2008. Enhanced performance measuring using OR: a case study, Journal of the Operational Research Society 59(6): 762-775.

http://dx.doi.org/10.1057/palgrave.jors.2602397

Serna, R. 2005. Where are the bank branches in my community? An analysis of branch distribution in low-income neighborhoods, California Reinvestment Coalition Report [online], [cited 17 February 2012]. Available from Internet: http://www.calreinvest.org

Suwignjo, P.; Bititci, U.; Carrie, A. 2000. Quantitative models for performance measurement system, International Journal of Production Economics 64(1/3): 231-241.

http://dx.doi.org/10.1016/S0925-5273(99)00061-4

Tarawneh, M. 2006. A comparison of financial performance in the banking sector: some evidence from Omani commercial banks, International Research Journal of Finance and Economics 3: $101-112$.

Weber, M; Borcherding, K. 1993. Behavioral influences on weight judgments in multiattribute decision making, European Journal of Operational Research 67(1): 1-12.

http://dx.doi.org/10.1016/0377-2217(93)90318-H

Wu, D.; Yang, Z.; Liang, L. 2006. Using DEA-neural network approach to evaluate branch efficiency of a large Canadian bank, Expert Systems with Applications 31(1): 108-115.

http://dx.doi.org/10.1016/j.eswa.2005.09.034

Yang, Z. 2009. Assessing the performance of Canadian bank branches using data envelopment analysis, Journal of the Operational Research Society 60(6): 771-780.

http://dx.doi.org/10.1057/palgrave.jors.2602619 
Fernando A. F. FERREIRA is an Assistant Professor at the ISCTE Business School of the University Institute of Lisbon, Portugal, and Adjunct Research Professor at the University of Memphis, TN, USA. He holds a PhD in Quantitative Methods Applied to Economics and Management from the University of Algarve, Portugal, and received his MSc in Economic and Business Sciences from the University of Algarve and the Technical University of Lisbon, Portugal. In 2009, he was granted with a Calouste Gulbenkian Foundation fellowship for Post-Doctoral studies at the Fogelman College of Business and Economics of the University of Memphis. He has authored books, book chapters, peer-reviewed papers and made many conference presentations. He has practical experience as a group facilitator, and has focused principally on strategic decision making and risk analysis.

Sérgio P. SANTOS is an Assistant Professor at the Faculty of Economics of the University of Algarve, and member of the Center for Advanced Studies in Management and Economics of the University of Évora, Portugal. He holds a PhD in Management Science from the University of Strathclyde, and a MA in Economics and Econometrics from the University of Manchester, UK. His main research interests include performance measurement and management in both the private and public sectors. He has published some of his research in international journals such as Omega, International Journal of Production and Operations Management, Journal of the Operational Research Society and Health Care Management Science.

Paulo M. M. RODRIGUES is an economist at the Economics and Research Department of the Banco de Portugal, and Professor of Econometrics at NOVA School of Business and Economics, Universidade Nova de Lisboa, Portugal. He received his PhD and MA from the University of Manchester, UK. Previously he was Associate Professor at the University of Algarve, Portugal, a Jean Monnet Fellow at the European University Institute in Florence, Italy, and Visiting Scholar at the University of Navarra, Spain, the Institute for Advanced Studies in Vienna, Austria, and the University of British Columbia, Vancouver, Canada.

Ronald W. SPAHR is a Professor and Former Chairman in the Department of Finance, Insurance and Real Estate of the Fogelman College of Business and Economics of the University of Memphis, TN, USA. He received his PhD and MBA from the University of Wisconsin-Madison, MS in Operations Management from the University of Southern California and BS in Mechanical Engineering from South Dakota State University. Previously, he was the National City Bank Distinguished Professor of Banking and Finance at the University of Illinois, Belk Distinguished Professor of Finance at the University of North Carolina and Professor of Finance at the University of Wyoming. He has also lectured at a number of European universities. 